\title{
Improving the validation of model-simulated crop yield response to climate change: an application to the EPIC model $^{*}$
}

\author{
William E. Easterling ${ }^{1, * *}$, Xiafen Chen ${ }^{1}$, Cynthia Hays ${ }^{1}$, James R. Brandle ${ }^{2}$, \\ Hehui Zhang ${ }^{2}$
}

${ }^{1}$ Department of Agricultural Meteorology, University of Nebraska-Lincoln, Lincoln, Nebraska 68583, USA

${ }^{2}$ Department of Forestry, Fisheries and Wildlife, University of Nebraska-Lincoln, Lincoln, Nebraska 68583, USA

\begin{abstract}
Crop models have been used extensively to simulate yield response to various scenarios of climate change. Such simulations have been inadequately validated, limiting their utility in policy analysis. In this research, it is argued that the performance of crop models during recent years of extreme weather conditions relative to current normals may give a better indication of the validity of model simulations of crop yields in response to climate change than performance during the full range of climate conditions (as is done now). Twenty years of the climate record (1971-1990) are separated into different growing season temperature and precipitation classes (normal years, hot/cold extremes, wet/dry extremes) for 7 weather stations in eastern Nebraska, USA. The Erosion Productivity Impact Calculator (EPIC), a crop growth model, is used to simulate crop yields with each of the above weather classes. Statistical comparisons are made between simulated yields, observed yields and observed yields detrended of technology influences. Based on these comparisons, we conclude that EPIC reliably simulates crop yields under temperature extremes, some which approach the types of climate conditions that may become more frequent with climate change. Simulations with precipitation extremes are less reliable than with the temperature extremes but are argued still to be credible. Confidence in crop simulations during years mimicking climate warming scenarios appears warranted.
\end{abstract}

KEY WORDS: Climate change $\cdot$ Crop model $\cdot$ Validation $\cdot$ Climate impacts $\cdot$ Ecological model

\section{INTRODUCTION}

A crop simulation model is a representation of a simplified crop production system, and it consists of nonlinear mathematical equations and logic to provide a systematic analysis of the crop production system (Ritchie 1991). Models of this type take into account underlying physiological processes of crop growth; they operate on a range of temporal resolutions: monthly, daily or even hourly time-step. They have been developed with different levels of biological details (Thornton et al. 1991) and run for different environmental conditions such as soil type, weather

\footnotetext{
- Jour. Ser. No. 11339 Nebraska Ag. Res. Div.

•-E-mail: agme014@unlvm.unl.edu
}

and management to simulate dynamic processes of crop growth and development. Yet, even the most physiologically-based crop models contain empirical relationships (e.g. growing degree-days to simulate phenology) subject to constraints imposed by the range of data observations from which the relationships were inductively or deductively derived.

The prospects of future climate changes from greenhouse warming have caused concern over their possible consequences for the production of food and fiber. Since the most immediate agricultural impacts of climate change will be on crop growth and economic yield (Tegart et al. 1990), considerable attention has focused on developing methods of predicting such impacts. Several recent benchmark studies have relied on crop simulation models of varying forms to estimate 
the yield response of agricultural crops to climate change and, in most cases, rising atmospheric carbon dioxide concentrations (e.g. Parry \& Carter 1988, Smith \& Tirpak 1990, Easterling et al. 1993, Rosenzweig \& Parry 1994).

Though validation ${ }^{1}$ procedures were followed in most of the above studies, they tended to be highly generalized - usually a correlation between observed and modeled yields with little analysis of the level of agreement between the two. We argue that the validity of crop simulation models under conditions of climate change has not been adequately established. The application of crop models, especially those with embedded empirical components, to problems of climate change has been criticized on grounds that the magnitude of anticipated climate change may exceed ranges of observed climate from which empirical relationships were estimated in the first place (Easterling et al. 1992).

The purpose of this study is to evaluate the reliability of crop model simulations of yields under extreme climate conditions versus simulations under climate conditions close to current normals. Specifically, we identify years in which mean growing season climate departed from normal over the period 1971-1990 in order to compare simulated yields from those years with simulated yields from years in which growing season climate was near 1971-1990 normals. Hence, we define extremes as those years generally falling toward the upper and lower bounds of the distribution of all years in the study period. Because of the distorting effect of technological progress on observed crop yield series, discussed below, we are not able to utilize extreme years prior to the study period. In both the extreme and normal climate cases, our analysis focuses on how well modeled yields predict observed yields. While we recognize that the range of climate conditions associated with anticipated global warming may rapidly exceed the range of climate conditions under the current climate, our premise is that the reliability of crop models in current extreme years gives a first approximation of the reliability of model estimates of

\footnotetext{
${ }^{1}$ Validation of physiologically-based crop models consists of 2 layers. The first layer is validation of 'cause and effect' in the individual equations of highly specific plant growth processes and is normally done with laboratory or field experimentation. The second layer is validation of simulations of plant growth based on the combination of individual equations. These studies above do not define validation as the establishment of cause and effect within the models but rather, more loosely, the reasonable strong covariance of the modeled results with reality. We stick to this second layer of definition of validation in this study since we believe that true validation, as used in the former sense, is more demanding and less relevant than called for in this application
}

yields in response to relatively more severe climate model scenarios of greenhouse warming. We use the Erosion Productivity Impact Calculator (EPIC; Williams et al. 1984) as one representative of a general class of crop growth models that has been used for climate change analysis. EPIC is described below.

Variations in yields are caused by numerous factors besides climate, especially over long time periods. A validation study of the kind reported here is complicated by the difficulty of separating the influences of technology change from climate on yields. New technologies have probably affected crop yields more than any other factor including climate over the last 40 or so years. We argue that past validations of crop models for climate change analysis have simply ignored the influence of technical change on yields over the period of the validation. In this study, the observed interannual yield data was detrended to control for technological progress in order to amplify the interannual yield variations due to weather factors.

\section{RECENT LITERATURE}

How valid are crop models for predicting current yields? Crop simulation models have been widely used in agronomic sciences for evaluation and forecast of crop growth rates and yields under various environmental and management conditions (Spitters 1990). The models have become accurate enough to be considered integral predictive tools in a variety of assessments such as the prediction of the long-term effects of soil erosion on crop productivity (USDA 1990) and management decision making (Jones et al. 1989).

The applications of crop simulation models to the climate change question are numerous. Most have examined the likely effects of changes in climate means and variability on crop yields, with and without the direct effects of carbon dioxide on plant growth and water use and a range of technological, management and policy adaptations that might be used to deal with the impacts of climate change. Examples of such studies include the assessment of climate impact on agriculture in semi-arid regions (Parry \& Carter 1988), the analysis of crop response to climate change (Curry et al. 1990), the specifications of the ideal model for predicting crop yields (e.g. Ritchie 1991), the analysis of effects of weather variability and soil parameters on the soil-crop-climate system (e.g. Protopapas \& Bras 1993), the simulation of crop responses to technology and adjustments (e.g. McKenney et al. 1992, Easterling et al. 1993, Rosenzweig \& Parry 1994), and the study of possible agricultural impacts of changed climate variability and the occurrence of extreme climate events (Mearns 1993). 


\section{METHODS}

3.1. Crop simulation model and location. EPIC is a mechanistic crop simulation model developed to estimate the relationship between soil erosion and crop productivity (Williams et al. 1984). EPIC simulates physically based processes that affect soil erosion and plant growth. The model includes components for weather simulation, hydrology, nutrient cycling, plant growth, tillage and crop management. EPIC operates on a daily time step.

Among factors simulated within EPIC are evapotranspiration (based on the Penman-Monteith model), soil temperature, crop potential growth, growth constraints (water stress, stress due to high or low temperature, nitrogen and phosphorus stress, and others) and yield. EPIC uses a single model for simulating all crops, although of course, each crop has unique values for the model parameters. The crop growth model uses light-use efficiency in calculating photosynthetic production of biomass. The potential biomass is adjusted daily for stress from the following factors: water, temperature, nutrients (nitrogen and phosphorus), aeration and radiation. Atmospheric $\mathrm{CO}_{2}$ concentrations influence photosynthesis through the light-use efficiency term and water use efficiency through the stomatal conductance term in the Penman Monteith model based on experimental results in the literature. It should be noted that we do not manipulate atmospheric $\mathrm{CO}_{2}$ concentration in this study - i.e. concentrations are held at current ambient levels. Crop yields are estimated by multiplying the above ground biomass at maturity (determined by accumulation of heat units or specified harvest date) by a harvest index (economic yield divided by above ground biomass) for the particular crop. Inputs for EPIC include information on soil data (for example, bulk density, water-holding capacity, wilting point) and management (for example, fertilization, tillage, planting, harvesting, irrigation, etc.).

The weather variables necessary for driving the EPIC model are daily values of precipitation, minimum/maximum air temperature, solar radiation, windspeed and relative humidity. EPIC provides options for simulating various combinations of 5 weather variables with a stochastic weather generator. Solar radiation and air temperature are simulated from monthly means of daily solar radiation and are adjusted for days with precipitation (Richardson 1981). Wind is simulated using a model developed by Richardson \& Wright (1984) which considers average daily velocity and daily direction. Relative humidity is simulated from monthly averages and is adjusted to account for days with precipitation (Williams et al. 1990). Precipitation is simulated by a first-order Markov chain model developed by Nicks (1974); inputs include monthly probabilities of receiving precipitation, average monthly precipitation and monthly standard deviation of daily precipitation. In this study, the weather generator was used only to generate daily windspeed, solar radiation and relative humidity; all other weather inputs were inserted directly as daily observations as described below.

EPIC has been subjected to numerous validation exercises. Extensive tests of EPIC simulations were conducted at over 150 sites and on more than 10 crop species and, generally, those tests concluded that EPIC adequately simulated crop yields under the range of observed weather conditions (Kiniry et al. 1990, Rosenberg et al. 1992). However, few, if any, efforts have been made to analyze the accuracy of the EPIC simulation model under extreme climate conditions approximating future climate changes.

Seven counties were arbitrarily selected to represent production in the eastern one-third of Nebraska (Fig. 1); such encompasses the major crop production area of
Fig. 1. Locations of weather stations in Nebraska, USA, and counties of representative farms used in EPIC

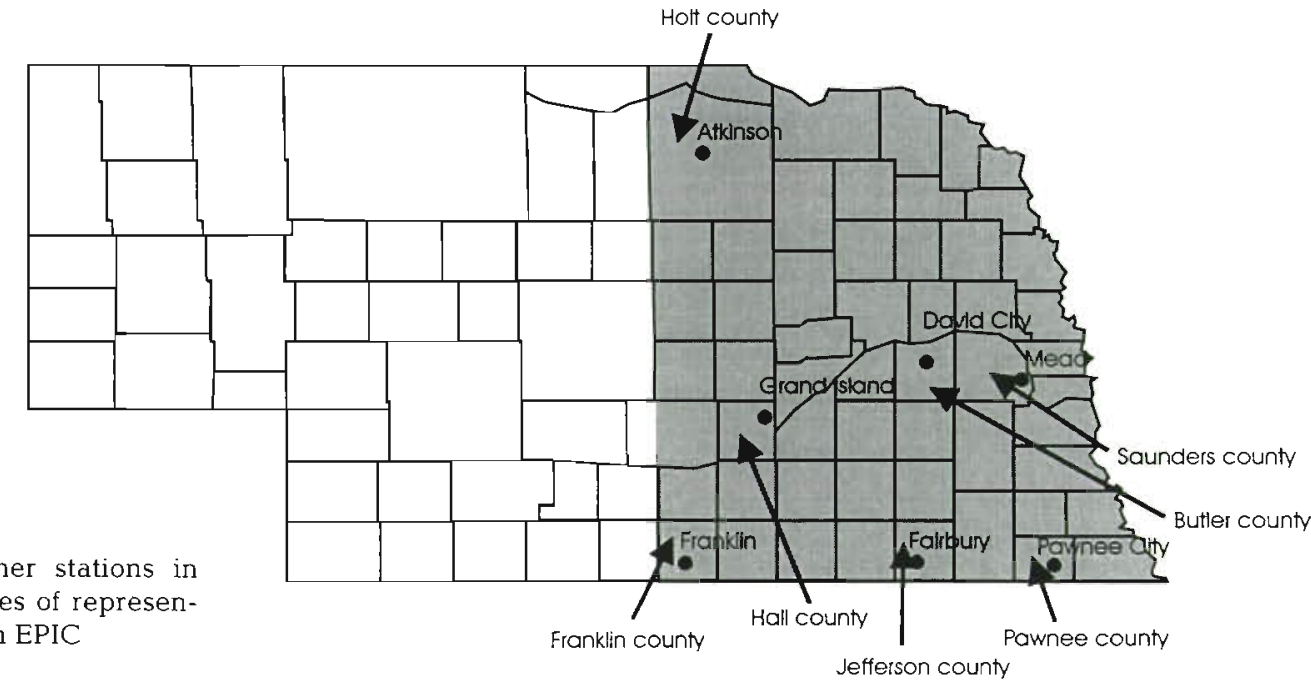


Table 1. Representative farm locations, crop type, irrigation/dryland practice, weather station locations and soils used in this study

\begin{tabular}{|llll|}
\hline Crop & County & Cooperative weather data & Soil type(s) \\
\hline Irrigated maize & Holt & Atkinson & Dunday, Valentine \\
Irrigated maize & Butler & David City & Crete \\
Irrigated maize & Hall & Grand Island & Holdredge \\
Dryland maize & Saunders & Mead & Sharpsburg \\
Dryland sorghum & Franklin & Franklin & Uly \\
Dryland maize & Jefferson & Fairbury & Wymore \\
Dryland sorghum & Pawnee & Pawnee City & Kennebic \\
\hline
\end{tabular}

the state. Eight farms for this study were constructed using the representative farms developed for a climate change impact study (the MINK project described by Easterling et al. 1992). Detailed profiles of relevant production characteristics (e.g. soils, weather, cultural practices) were compiled for each representative farm in the MINK study. Such profiles for the 8 farms chosen from 7 counties in Nebraska are shown in Table 1 . Holt county was represented by 2 farms with different soil types. Results from the 2 farms in Holt County were averaged to represent the county. Cooperative weather station locations are identified for each county in Fig. 1.

Weather data for EPIC included observed daily maximum and minimum temperature and precipitation totals from each of the cooperative weather stations. Mean daily solar radiation, relative humidity and windspeed were not available from the cooperative stations, so they were generated stochastically from monthly means at the nearest first order station using aforementioned procedures. The observed and stochastically generated daily climate data were combined into one EPIC input data set per county for the 1971-1990 period. EPIC was given the 1971-1990 daily climate inputs replayed 10 times in succession for a total of $200 \mathrm{yr}$ per EPIC run at each county (i.e. the 1971-1990 daily climate was cloned 10 times and the clones were concatenated to form the 200 yr of input data to EPIC) in order to minimize simulated crop yield distortions introduced by EPIC's initial values for cumulative crop environment controls such as water balance and soil nutrient levels. Simulated yields were averaged to provide one value for each year for each county. Such was consistent with previous model applications (Easterling et al. 1992). Though admittedly not a robust means of scaling, such averaging is consistent with procedures followed in most previous model-based studies of the crop yield impacts of climate change.

3.2. Identification of climate extremes. Temperature ex-tremes were arbitrarily identified by ranking years (1971-1990) by their growing season (April 1 to Sep- tember 30) temperature means and assigning the 5 years that were either coldest or hottest to the appropriate category (hot or cold) - the 10 middle years are considered normal. The same procedure was used for identifying growing season precipitation extremes (wet or dry). The division between the extremes and normal are arbitrary (i.e. no real difference between the 5 th and 6 th year of wettest growing season precipitation), although gradual natural breaks make for distinct differences between the normal and extreme groups (Table 2). No statistical tests were performed to determine if differences between extreme and normal means were significant, primarily because there was no known agronomic reason for doing so. The difference between the 1971-1990 mean growing season temperature and the extreme temperatures is greater than $+0.9^{\circ} \mathrm{C}$ for the hot extremes and $-0.7^{\circ} \mathrm{C}$ for the cold extreme. The difference between the average normal precipitation and the extreme precipitation categories is greater than $\pm 140 \mathrm{~mm}$.

Concerning the severity and/or frequency of extreme events during the 1971-1990 period relative to other eras, the only necessary condition for successful testing of our stated premise is that such extremes were noticeably different from the climate normals during the period in which the crop model was calibrated (which, in the case of EPIC, is amply bracketed

Table 2. Means and ranges over the 7 cooperative weather stations combined of growing season average daily temperature and total precipitation

\begin{tabular}{|lcc|}
\hline Climate classification & Mean & Range \\
\hline Hottest 5 years & $20.4^{\circ} \mathrm{C}$ & $18.6-22.2^{\circ} \mathrm{C}$ \\
$\begin{array}{l}\text { Normal temperature } \\
\text { (middle 10 years) }\end{array}$ & $19.4^{\circ} \mathrm{C}$ & $17.9-21.4^{\circ} \mathrm{C}$ \\
Coldest 5 years & $18.7^{\circ} \mathrm{C}$ & $16.6-20.5^{\circ} \mathrm{C}$ \\
Wettest 5 years & $677 \mathrm{~mm}$ & $517-899 \mathrm{~mm}$ \\
$\begin{array}{l}\text { Normal precipitation } \\
\text { (middle 10 years) }\end{array}$ & $506 \mathrm{~mm}$ & $394-726 \mathrm{~mm}$ \\
Driest 5 years & $363 \mathrm{~mm}$ & $243-490 \mathrm{~mm}$ \\
\hline
\end{tabular}


Table 3. Extreme rankings of mean temperature and total precipitation during the growing season for the years in the $1971-1990$ period when compared to the entire length of record for the cooperative weather location (85 to 96 yr) up through 1991

\begin{tabular}{|c|c|c|c|c|c|c|c|c|}
\hline \multirow{2}{*}{$\begin{array}{l}\text { Cooperative weather } \\
\text { data location }\end{array}$} & \multicolumn{2}{|c|}{ Warmest } & \multicolumn{2}{|c|}{ Coolest } & \multicolumn{2}{|c|}{ Wettest } & \multicolumn{2}{|c|}{ Driest } \\
\hline & Ranking & Year & Ranking & Year & Ranking & Year & Ranking & Year \\
\hline Atkinson & $2 n d$ & 1988 & 11 th & 1979 & 2nd & 1986 & $8 \mathrm{th}$ & 1974 \\
\hline David City & 8 th & 1977 & 12 th & 1982 & $3 \mathrm{rd}$ & 1982 & 5 th & 1976 \\
\hline Grand Island & 13 th & 1977 & 6 th & 1982 & 3 rd & 1977 & 10 th & 1976 \\
\hline Franklin & 6 th & 1977 & 5 th & 1982 & 6th & 1981 & 6 th & 1980 \\
\hline Fairbury & $33 r d$ & 1977 & 5 th & 1982 & 5th & 1977 & $3 \mathrm{rd}$ & 1974 \\
\hline Pawnee City & 5 th & 1980 & 27 th & 1979 & 11 th & 1978 & 2nd & 1980 \\
\hline
\end{tabular}

by the 1971-1990 period). Of course, the more frequent and severe the extremes were during the 1971-1990 period, relative to the long-term means, the stronger our inferences can be to the validity of crop simulations under climate change. Though the frequencies of growing season temperature and/or precipitation extremes in the 1971-1990 period were not as great as in other historical eras in the region (e.g. the droughts of the 1930s and 1950s), the differences between the 1971-1990 normal and extreme categories described above were noticeable, and several individual seasons during 1971-1990 ranked highly as extremes over the entire length of record (Table 3). Furthermore, it is worth mentioning that the departure from normal of the above categories of hot and dry extremes exceed the mean departures from normal for temperature and precipitation during the 1930 s as reported by Easterling et al. (1993). Thus, we are confident that the 1971-1990 period permits an adequate test of our premise.

The establishment of an optimal length of climate record for the study involves a difficult trade-off between having enough years for compelling statistical analysis versus having so long a time period as to span significantly different technological eras. A computerized data base, Climprob (Meyer et al. 1996) was used to compare interannual assemblages of climate extremes identified above with normals from different lengths of record for 6 of the 7 cooperative stations (the Mead station was started in 1968). Average daily temperature and total precipitation were examined over the growing season (April 1 to September 30) for 1971-1990. The 1961-1970 period was incrementally added to the 1971-1990 period to determine how much information was foregone by focusing only on 1971-1990. Adding the 1961-1970 period caused no changes to the dry extreme of precipitation. The ranges of temperature and the wet extreme of precipitation were only changed at half or less of the stations (usually the southern stations). Since the addition of the 1961-1970 period caused only minor changes in the central tendencies of the temperature and precipi- tation observations, with the exception of temperature at Franklin and Fairbury, it was decided only to examine the 1971-1990 period.

Temperature and precipitation means over the entire period of record for the above stations were developed in order to determine the representativeness of the 1971-1990 period, especially the 10 normal years within the 1971-1990 period, vis-á-vis the long-term means. The differences between the means for the entire length of record, 1971-1990 record, and the 10 normal years within the $1971-1990$ record were mostly slight and of little meaningful consequence (Table 4). The temperature means varied by an average of $0.4^{\circ} \mathrm{C}$ among the periods and the total precipitation means varied by an average of $21.5 \mathrm{~mm}$. The means over the 6 stations for the entire length of record available (Table 4) agree well with the means of the normal years over the 7 stations shown in Table 2 (19.59 versus $19.41^{\circ} \mathrm{C}$ and 472 versus $478 \mathrm{~mm}$ ).

3.3. Separating effects of technological change and climate on yields. Actual or observed yields for this study were from county level estimates for the $20 \mathrm{yr}$ period obtained from the National Agricultural Statistics Services (USDA 1971-1990).

The observed yields were detrended in a conventional manner (e.g. McQuigg et al. 1973, Sakamoto 1978) using a simple linear regression model (with time as the independent predictor of yield) to remove the technology influence on production. The logic of this procedure is rooted in the recent (since World War II particularly) observed upward trend in yields of virtually all crops in the U.S., but especially maize. This trend is easily captured in a simple linear regression model, leaving the residuals to indicate year-to-year variations in yields due to weather. The point of origin for the regression was 1984 (the beginning of the 1984-1987 period that best captures the level of technology embedded in EPIC), therefore the observed yields before 1984 would be increased and the observed yields after 1984 would be decreased in order to simulate a period of approximately constant technology. Figs. $2 \& 3$ are examples showing that, as 
Table 4. Growing season means and standard deviations (SD) of daily temperatures and precipitation for 3 lengths of data record (total record through 1991, $1971-1990$ period, and the 10 normal years embedded in the $1971-1990$ period

\begin{tabular}{|c|c|c|c|c|c|}
\hline \multirow{2}{*}{$\begin{array}{l}\text { Cooperative weather data } \\
\text { location and county }\end{array}$} & \multirow{2}{*}{$\begin{array}{l}\text { Length of } \\
\text { record }(y r)\end{array}$} & \multicolumn{2}{|c|}{ Average dally temperature $\left({ }^{\circ} \mathrm{C}\right)$} & \multicolumn{2}{|c|}{ Total precipitation (mm) } \\
\hline & & Mean & $\mathrm{SD}$ & Mean & $\mathrm{SD}$ \\
\hline \multirow{3}{*}{$\begin{array}{l}\text { Atkinson, Holt County } \\
\text { (irrigated maize) }\end{array}$} & 85 & 18.0 & 1.0 & 415 & 108 \\
\hline & 20 & 18.2 & 0.7 & 459 & 107 \\
\hline & 10 & 18.2 & 0.2 & 460 & 46 \\
\hline \multirow{3}{*}{$\begin{array}{l}\text { David City, Butler County } \\
\text { (irrigated maize) }\end{array}$} & 94 & 19.3 & 1.0 & 538 & 152 \\
\hline & 20 & 19.2 & 0.7 & 550 & 174 \\
\hline & 10 & 19.1 & 0.3 & 521 & 90 \\
\hline \multirow{3}{*}{$\begin{array}{l}\text { Franklin, Franklin County } \\
\text { (dryland sorghum) }\end{array}$} & 90 & 20.0 & 1.0 & 456 & 124 \\
\hline & 20 & 19.6 & 0.8 & 478 & 102 \\
\hline & 10 & 19.6 & 0.3 & 479 & 37 \\
\hline \multirow{3}{*}{$\begin{array}{l}\text { Grand Island, Hall County } \\
\text { (irrigated maize) }\end{array}$} & 92 & 19.4 & 1.0 & 480 & 142 \\
\hline & 20 & 19.3 & 0.6 & 466 & 126 \\
\hline & 10 & 19.3 & 0.1 & 451 & 38 \\
\hline \multirow{3}{*}{$\begin{array}{l}\text { Fairbury, Jefferson County } \\
\text { (dryland maize) }\end{array}$} & 96 & 20.2 & 1.1 & 563 & 146 \\
\hline & 20 & 19.5 & 0.6 & 562 & 136 \\
\hline & 10 & 19.5 & 0.2 & 558 & 51 \\
\hline \multirow{3}{*}{$\begin{array}{l}\text { Pawnee City, Pawnee County } \\
\text { (dryland sorghum) }\end{array}$} & 88 & 20.7 & 1.1 & 580 & 160 \\
\hline & 20 & 21.1 & 0.6 & 577 & 136 \\
\hline & 10 & 21.1 & 0.3 & 590 & 64 \\
\hline \multicolumn{2}{|c|}{ Mean for $80+$ yr record over all locations } & 19.6 & & 505 & \\
\hline
\end{tabular}

expected, the detrended observed yields (hereafter referred to as 'detrended yields') are larger than the observed yields prior to 1984 and smaller than the observed yields after 1984 (keeping in mind that EPIC was calibrated to reflect technologies of the 1984-1987 period) for Holt County and Franklin County locations. The other 5 locations were similar. Tables $5 \& 6$ also show that the detrended yield coefficient of variation

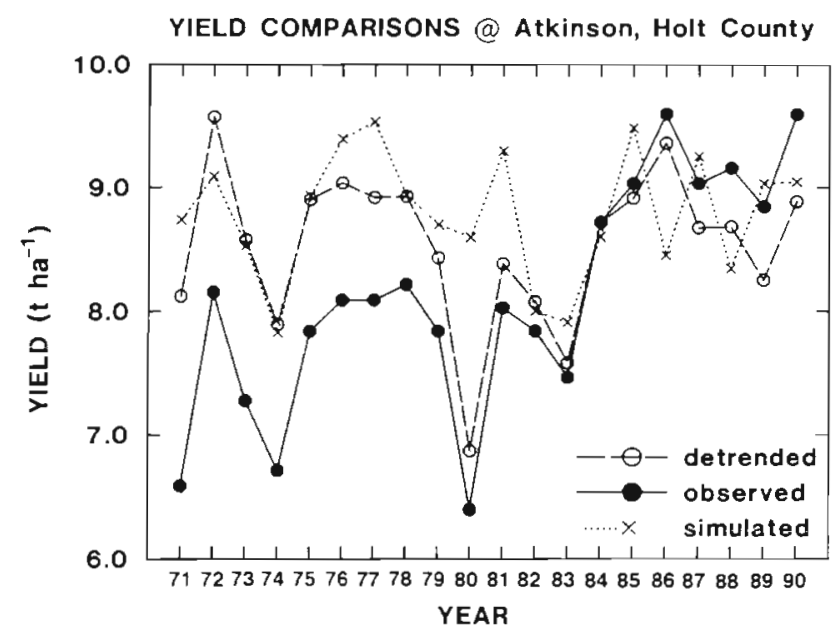

Fig. 2. Time series (1971-1990) of simulated, observed and detrended irrigated maize yields with Atkinson weather and a Holt County representative farm
$(\mathrm{CV})$ is usually smaller than that of the observed yields. Also the detrended yields $\mathrm{CV}$ is closer in magnitude to the simulated yields than the observed yields CV. The difference between the low CV for simulated and detrended yields versus the relatively high $\mathrm{CV}$ for observed yields quantifies the distortion technological change superimposes on year-to-year variations in yields due to climate variation.

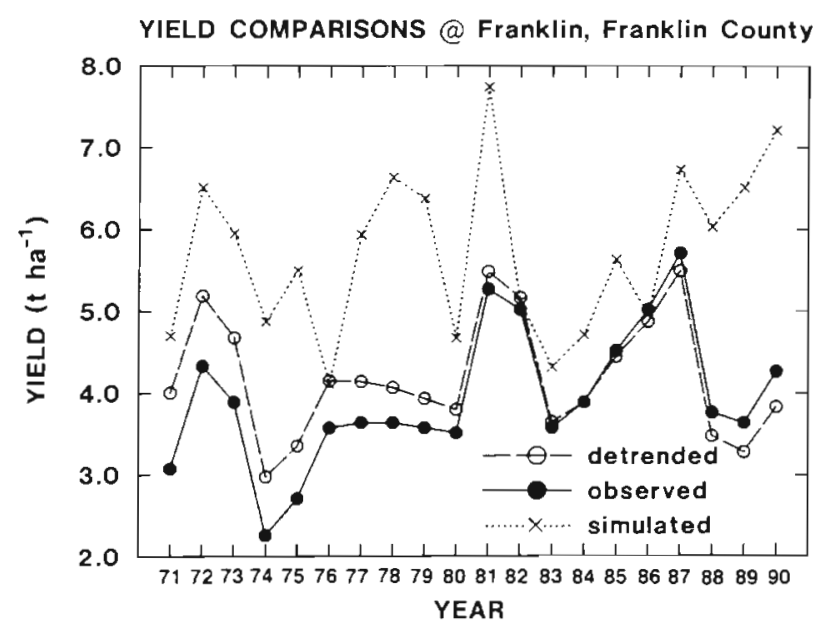

Fig. 3. Time series (1971-1990) of simulated, observed and detrended dryland sorghum with Franklin weather and a Franklin County representative farm 
Table 5. Temperature ranges and simulated, observed and detrended yield mean, standard deviation (SD), and coefficient of variation [CV; computed as: $(\mathrm{SD} / \mathrm{Mean}) \times 100]$

\begin{tabular}{|c|c|c|c|c|c|c|c|c|c|c|}
\hline \multirow{2}{*}{$\begin{array}{l}\text { Cooperative weather data } \\
\text { location and county }\end{array}$} & \multirow{2}{*}{$\begin{array}{l}\text { Temperature } \\
\text { range }\left({ }^{\circ} \mathrm{C}\right)\end{array}$} & \multicolumn{3}{|c|}{ Simulated yields ( $\mathrm{h} \mathrm{a}^{-1}$ ) } & \multicolumn{3}{|c|}{ Observed yields (t ha-1) } & \multicolumn{3}{|c|}{ Detrended yields ( $t h a^{-1}$ ) } \\
\hline & & Mean & $\mathrm{SD}$ & $\mathrm{CV}$ & Mean & $\mathrm{SD}$ & $\mathrm{CV}$ & Mean & $\mathrm{SD}$ & $\mathrm{CV}$ \\
\hline \multirow{3}{*}{$\begin{array}{l}\text { Atkinson, Holt County } \\
\text { (irrigated maize) }\end{array}$} & $16.6-17.6$ & 8.73 & 0.43 & 4.93 & 7.98 & 0.19 & 2.38 & 8.78 & 0.57 & 6.49 \\
\hline & $17.9-18.6$ & 8.69 & 0.58 & 6.67 & 7.70 & 1.01 & 13.12 & 8.35 & 0.75 & 8.98 \\
\hline & $18.6-19.8$ & 9.03 & 0.43 & 4.76 & 9.13 & 0.28 & 3.07 & 8.68 & 0.26 & 3.00 \\
\hline \multirow{3}{*}{$\begin{array}{l}\text { David City, Butler County } \\
\text { (irrigated maize) }\end{array}$} & $18.1-18.7$ & 9.84 & 0.66 & 6.71 & 8.35 & 0.83 & 9.94 & 8.43 & 0.46 & 5.46 \\
\hline & $18.7-19.6$ & 9.59 & 0.67 & 6.99 & 7.49 & 1.12 & 14.95 & 8.28 & 0.92 & 11.11 \\
\hline & $19.6-20.7$ & 9.75 & 0.39 & 4.00 & 7.65 & 1.39 & 18.17 & 7.84 & 0.88 & 11.22 \\
\hline \multirow{3}{*}{$\begin{array}{l}\text { Franklin, Franklin County } \\
\text { (dryland sorghum) }\end{array}$} & $18.4-19.0$ & 5.84 & 1.02 & 17.47 & 4.26 & 0.54 & 12.68 & 4.12 & 0.71 & 17.23 \\
\hline & $19.2-19.9$ & 5.81 & 1.13 & 19.45 & 3.86 & 1.04 & 26.94 & 4.24 & 0.92 & 21.70 \\
\hline & $19.9-21.8$ & 5.38 & 0.87 & 16.17 & 3.78 & 0.73 & 19.31 & 4.17 & 0.41 & 9.83 \\
\hline \multirow{3}{*}{$\begin{array}{l}\text { Grand Island, Hall County } \\
\text { (irrigated maize) }\end{array}$} & $18.0-18.8$ & 9.45 & 0.81 & 8.57 & 7.93 & 0.51 & 6.43 & 8.77 & 0.53 & 6.04 \\
\hline & $19.0-19.6$ & 9.49 & 1.45 & 15.28 & 8.04 & 0.89 & 11.07 & 8.36 & 0.63 & 7.54 \\
\hline & $19.6-20.5$ & 9.78 & 0.51 & 5.21 & 8.32 & 1.54 & 18.51 & 8.36 & 1.03 & 12.32 \\
\hline \multirow{3}{*}{$\begin{array}{l}\text { Mead, Saunders County } \\
\text { (dryland maize) }\end{array}$} & $18.4-18.8$ & 4.11 & 1.52 & 36.98 & 5.10 & 1.20 & 23.53 & 5.88 & 1.31 & 22.28 \\
\hline & $18.8-19.4$ & 4.99 & 1.03 & 20.64 & 5.15 & 1.84 & 35.73 & 5.46 & 1.57 & 28.75 \\
\hline & $20.0-20.9$ & 4.31 & 0.80 & 18.56 & 4.84 & 1.27 & 26.24 & 5.00 & 0.97 & 19.40 \\
\hline \multirow{3}{*}{$\begin{array}{l}\text { Fairbury, Jefferson County } \\
\text { (dryland maize) }\end{array}$} & $18.4-18.9$ & 5.01 & 1.27 & 25.35 & 5.31 & 0.77 & 14.50 & 5.32 & 0.93 & 17.48 \\
\hline & $19.2-19.8$ & 4.62 & 1.58 & 34.20 & 3.99 & 1.06 & 26.57 & 4.59 & 1.02 & 22.22 \\
\hline & $19.8-20.7$ & 4.50 & 1.64 & 36.44 & 4.48 & 1.39 & 31.03 & 4.51 & 1.19 & 26.39 \\
\hline \multirow{3}{*}{$\begin{array}{l}\text { Pawnee City, Pawnee County } \\
\text { (dryland sorghum) }\end{array}$} & $20.2-20.5$ & 6.06 & 0.66 & 10.89 & 3.96 & 1.10 & 27.78 & 4.16 & 1.32 & 31.73 \\
\hline & $20.5-21.4$ & 5.62 & 1.00 & 17.79 & 4.07 & 1.15 & 28.26 & 4.16 & 1.00 & 24.04 \\
\hline & $21.6-22.2$ & 5.50 & 0.90 & 16.36 & 3.30 & 0.56 & 16.97 & 3.45 & 0.58 & 16.81 \\
\hline
\end{tabular}

Table 6. Precipitation ranges and simulated, observed and detrended yield mean, standard deviation (SD), and coefficient of variation $[\mathrm{CV}$; computed as: (SD/Mean) $\times 100]$

\begin{tabular}{|c|c|c|c|c|c|c|c|c|c|c|}
\hline \multirow{2}{*}{$\begin{array}{l}\text { Cooperative weather data } \\
\text { location and county }\end{array}$} & \multirow{2}{*}{$\begin{array}{l}\text { Precipitation } \\
\text { range ( } \mathrm{mm} \text { ) }\end{array}$} & \multicolumn{3}{|c|}{ Simulated yields $\left(\mathrm{t} \mathrm{ha}^{-1}\right)$} & \multicolumn{3}{|c|}{ Observed yields $\left(\mathrm{tha}^{-1}\right)$} & \multicolumn{3}{|c|}{ Detrended yields $\left(t \mathrm{ha}^{-1}\right)$} \\
\hline & & Mean & $\mathrm{SD}$ & $\mathrm{CV}$ & Mean & SD & $\mathrm{CV}$ & Mean & $\mathrm{SD}$ & $\mathrm{CV}$ \\
\hline \multirow{3}{*}{$\begin{array}{l}\text { Atkinson, Holt County } \\
\text { (irrigated maize) }\end{array}$} & $266-380$ & 8.73 & 0.55 & 6.30 & 7.76 & 1.20 & 15.46 & 8.12 & 0.80 & 9.85 \\
\hline & $396-513$ & 8.74 & 0.55 & 6.29 & 8.10 & 0.76 & 9.38 & 8.49 & 0.46 & 5.42 \\
\hline & $523-709$ & 8.93 & 0.45 & 5.04 & 8.54 & 1.02 & 11.94 & 9.06 & 0.40 & 4.42 \\
\hline \multirow{3}{*}{$\begin{array}{l}\text { David City, Butler County } \\
\text { (irrigated maize) }\end{array}$} & $309-407$ & 9.85 & 0.52 & 5.28 & 7.21 & 1.57 & 21.78 & 7.79 & 1.06 & 13.61 \\
\hline & $412-726$ & 9.67 & 0.75 & 7.76 & 8.12 & 1.00 & 12.32 & 8.44 & 0.71 & 8.41 \\
\hline & $735-899$ & 9.59 & 0.30 & 3.13 & 7.53 & 0.76 & 10.09 & 8.16 & 0.74 & 9.07 \\
\hline \multirow{3}{*}{$\begin{array}{l}\text { Franklin, Franklin County } \\
\text { (dryland sorghum) }\end{array}$} & $299-369$ & 4.78 & 0.12 & 2.51 & 3.55 & 1.02 & 28.73 & 3.91 & 0.68 & 17.39 \\
\hline & $398-517$ & 5.84 & 0.95 & 16.27 & 3.90 & 0.80 & 20.51 & 4.10 & 0.75 & 18.29 \\
\hline & $519-686$ & 6.39 & 1.06 & 16.59 & 4.42 & 0.71 & 16.06 & 4.66 & 0.69 & 14.81 \\
\hline \multirow{3}{*}{$\begin{array}{l}\text { Grand Island, Hall County } \\
\text { (irrigated maize) }\end{array}$} & $243-393$ & 9.89 & 0.56 & 5.66 & 7.75 & 1.39 & 17.94 & 8.22 & 1.06 & 12.90 \\
\hline & $398-500$ & 9.75 & 1.00 & 10.26 & 8.17 & 0.87 & 10.65 & 8.66 & 0.69 & 7.97 \\
\hline & $517-796$ & 8.83 & 1.51 & 17.10 & 8.25 & 0.81 & 9.82 & 8.30 & 0.38 & 4.58 \\
\hline \multirow{3}{*}{$\begin{array}{l}\text { Mead, Saunders County } \\
\text { (dryland maize) }\end{array}$} & $334-387$ & 3.69 & 0.66 & 17.89 & 4.36 & 1.36 & 31.19 & 5.09 & 1.14 & 22.40 \\
\hline & $394-557$ & 4.76 & 1.11 & 23.32 & 4.76 & 1.54 & 32.35 & 5.01 & 1.37 & 27.35 \\
\hline & $597-797$ & 5.49 & 0.78 & 14.21 & 6.35 & 0.78 & 12.28 & 6.68 & 0.78 & 11.68 \\
\hline \multirow{3}{*}{$\begin{array}{l}\text { Fairbury, Jefferson County } \\
\text { (dryland maize) }\end{array}$} & $291-448$ & 3.77 & 1.41 & 37.40 & 3.73 & 1.22 & 32.71 & 4.14 & 1.13 & 27.29 \\
\hline & $495-671$ & 4.33 & 1.09 & 25.17 & 4.48 & 1.23 & 27.46 & 4.68 & 1.06 & 22.65 \\
\hline & $678-871$ & 6.34 & 0.79 & 12.46 & 5.07 & 0.69 & 13.61 & 5.52 & 0.38 & 6.88 \\
\hline \multirow{3}{*}{$\begin{array}{l}\text { Pawnee City, Pawnee County } \\
\text { (dryland sorghum) }\end{array}$} & $339-490$ & 5.42 & 0.80 & 14.76 & 3.60 & 1.11 & 30.83 & 3.73 & 0.92 & 24.66 \\
\hline & $490-675$ & 5.54 & 1.02 & 18.41 & 3.81 & 1.15 & 30.18 & 3.92 & 1.17 & 29.85 \\
\hline & $693-785$ & 6.30 & 0.35 & 5.56 & 4.19 & 0.78 & 18.62 & 4.38 & 0.76 & 17.35 \\
\hline
\end{tabular}




\section{RESULTS}

While simulated yields do not always show good agreement with observed and/or detrended yields, the simulated yields usually follow the same trend (decreasing or increasing) as the observed and/or detrended yields. Figs. $2 \& 3$ show this for Holt County and Franklin County as examples. Figs. 2 \& 3 also suggest that the simulated yields show better agreement with detrended yields than with observed yields, underscoring the importance of removing the technology influence on yields. Examination of years where the simulated yields do not agree with either observed or detrended yields revealed no discernable relationship between the lack of agreement and whether or not the climate was classified as extreme or normal for those particular years.

Mean absolute errors (MAE) and mean bias errors (MBE) are used to describe the differences among simulated, observed and detrended yields over the normal and extreme climate categories. MAEs, the mean absolute difference between simulated and observed/ detrended yields, measure the total spread between simulated and observed/detrended yields (Table 7). MAEs averaged over all counties per climate category are uniformly lower for detrended yields than observed yields. The range of MAEs for detrended yields among climate categories was exceedingly small: 1.091 to 1.299 metric tons per hectare $\left(t \mathrm{th}^{-1}\right)$.

MBEs, the average difference (positive and negative differences summed together potentially to cancel) between the simulated and observed and/or detrended yields, measure the skewness of simulated yields, if any, either toward overprediction or underprediction of observed and detrended yields. They

Table 7 Mean absolute error (MAE) and mean bias error (MBE) between EPIC yield and observed or detrended yield averaged over all counties. MAE computed as $N^{-1} \sum|(S-O)|$ and MBE computed as $N^{-1} \sum(S-O)$; where $N$ is number of cases, $S$ is EPIC yield and $O$ is observed/detrended yield Values in $\mathrm{tha}^{-1}$

\begin{tabular}{|lcccc}
\hline $\begin{array}{l}\text { Climate } \\
\text { classification }\end{array}$ & \multicolumn{2}{c}{ Observed yield } & \multicolumn{2}{c}{ Detrended yield } \\
\hline MAE & MBE & MAE & MBE \\
$\begin{array}{l}\text { Hottest 5 years } \\
\text { Normal temperature }\end{array}$ & 1.371 & 0.965 & 1.212 & 0.889 \\
(middle 10 years) & 1.515 & 1.218 & 1.178 & 0.770 \\
$\begin{array}{l}\text { Coldest 5 years } \\
\text { Wettest 5 years }\end{array}$ & 1.283 & 0.919 & 1.160 & 0.552 \\
$\begin{array}{l}\text { Normal precipitation } \\
\text { (middle 10 years) }\end{array}$ & 1.513 & 1.039 & 1.091 & 0.760 \\
Driest 5 years & 1.552 & 1.167 & 1.299 & 0.732 \\
\hline
\end{tabular}

reaffirm the MAE results showing that the spread between simulated and detrended yields is smaller than between simulated and observed yields in all climate categories (Table 7). Their overall positive values also indicate a tendency for simulated yields to overpredict observed and detrended yields across the climate categories. MBEs are smaller than the MAEs, meaning that, though the overall tendency is slightly toward overprediction of yields in the simulations, substantial underprediction is occurring too. Like the MAEs, the range of MBEs for detrended yields among climate categories was small (0.552 to $\left.0.889 \mathrm{t} \mathrm{ha}^{-1}\right)$.

Analysis of variance (ANOVA) was used to analyze the differences in MAEs among simulated, detrended and observed yields for the normal and extreme climate categories. We chose to focus only on MAEs because such give a better measure of total positive and negative error than MBEs. ANOVA permitted a robust means of determining how closely EPIC simulations agree with reality over a range of climate conditions, especially those conditions that approximate climate change. Our null hypothesis is that absolute differences between simulated and observed or between simulated and detrended yields are the same in extreme climate years and normal climate years.

ANOVA initially was used to test whether or not MAEs measuring agreement between simulated and observed or detrended yields were significantly different. The MAE time series of each climate category were averaged at each of the 7 counties producing 14 MAE observations (one for each pairing of simulated versus observed and simulated versus detrended yields). This procedure minimized problems with serial correlation. County and yield type (observed or detrended yields) interactions were modeled. The county interaction enables evaluation of the significance of plot effects (i.e. different crop species and whether or not irrigation is used) in determining differences between simulated and observed or detrended yields over the range of climate categories. The yield type interaction enables evaluation of the significance of differences between observed and detrended MAEs. The results of the ANOVA show that differences between the MAEs are significant for both the county $(\operatorname{Pr}>F=0.0024)$ and yield type $(\operatorname{Pr}>F=$ 0.0352).

The significance of the county differences is confirmation that the agreement between simulated and observed or detrended yields varies by crop species and irrigation versus dryland practices. The significance of the yield type interaction, along with the generally smaller spread between simulated and detrended yields than between simulated and observed yields - shown by the MBEs and MAEs 
above - confirms that the removal of the technology trend from the actual yield series is required for comparison with yield series simulated with constant technology

The second ANOVA was used to determine whether MAEs from the observed and detrended yield series are significantly different over the temperature categories. Here, the MAE time series was averaged by county and temperature category producing $21 \mathrm{MAE}$ observations (one for each county and temperature category). County and temperature category interactions were modeled. For the MAEs calculated with observed yields, the differences between counties, again, were highly significant $(\operatorname{Pr}>F=0.0004)$ while differences between temperature categories were not significant $(\operatorname{Pr}>F=0.3160)$. For the MAEs calculated with detrended yields, the differences between counties were highly significant $(\mathrm{Pr}>F=0.0027$ ) while differences between temperature categories were not significant $(\mathrm{Pr}>F=0.9534)$.

The significance of the county interactions signals differences in MAEs between maize and sorghum and between irrigation and dryland practices. Close examination of detrended MAEs, by temperature category,

Table 8. Mean absolute error (MAE) and mean bias error (MBE) differences between EPIC yield and observed or detrended yield for each temperature classification and county. Values in $\mathrm{tha}^{-1}$

\begin{tabular}{|lrrrr|}
\hline \multirow{2}{*}{ County } & \multicolumn{3}{c}{ Observed yield } & \multicolumn{2}{c|}{ Detrended yield } \\
& MAE & MBE & MAE & MBE \\
\hline Hottest 5 years & & & & \\
$\quad$ Holt & 0.445 & -0.101 & 0.485 & 0.350 \\
Butler & 2.098 & 2.098 & 1.913 & 1.913 \\
Franklin & 1.628 & 1.603 & 1.202 & 1.202 \\
Hall & 1.476 & 1.464 & 1.421 & 1.421 \\
Saunders & 0.657 & -0.533 & 0.688 & -0.688 \\
Jefferson & 1.096 & 0.026 & 0.742 & -0.010 \\
Pawnee & 2.197 & 2.197 & 2.034 & 2.034 \\
& & & & \\
Normal temperature (middle & 10 & years) & & \\
Holt & 1.245 & 0.993 & 0.569 & 0.343 \\
Butler & 2.107 & 2.107 & 1.314 & 1.314 \\
Franklin & 1.949 & 1.949 & 1.585 & 1.577 \\
Hall & 1.730 & 1.449 & 1.395 & 1.136 \\
Saunders & 0.988 & -0.154 & 1.063 & -0.462 \\
Jefferson & 1.041 & 0.633 & 0.864 & 0.029 \\
Pawnee & 1.547 & 1.547 & 1.454 & 1.454 \\
Coldest 5 years & & & & \\
Holt & & & & \\
Butler & 0.754 & 0.754 & 0.173 & -0.050 \\
Franklin & 1.481 & 1.481 & 1.402 & 1.402 \\
Hall & 1.571 & 1.571 & 1.732 & 1.715 \\
Saunders & 1.522 & 1.522 & 0.724 & 0.676 \\
Jefferson & 0.871 & -0.695 & 1.467 & -1.467 \\
Pawnee & 0.685 & -0.296 & 0.717 & -0.314 \\
& 2.096 & 2.096 & 1.902 & 1.902 \\
\hline
\end{tabular}

reveals Holt County irrigated maize is always lowest indicating the best agreement between simulated and detrended yields while sorghum (Pawnee County or Franklin County) is highest indicating least agreement except during warm extremes where Franklin is displaced by Butler County irrigated maize (Table 8). Dryland maize at Jefferson County has the secondbest agreement in all climate categories except where it is displaced by Saunders County dryland maize in warm extremes. Furthermore, the MAEs for the other 2 irrigated maize locations (Butler County and Hall County) tend to be substantially higher than for Holt County irrigated maize in all temperature categories. We are hard-pressed to find consistent site differences between the temperature categories that might suggest that different crops or irrigation versus dryland practices behave differently in normal versus extreme temperature years. Moreover, the lack of significance of the temperature category interaction suggests that, even though there is variation among crops and irrigation versus dryland, the level of agreement between simulated and both observed and detrended yields does not vary among the normal and extreme temperature categories.

The third ANOVA was used to determine whether MAEs from the observed and detrended series were significantly different over the precipitation categories. Again, MAEs were averaged by county and by precipitation category producing 21 observations. County and precipitation category interactions were modeled. For the MAEs calculated with observed yields, the differences between counties were significant $(\operatorname{Pr}>F=0.0059$ ) while differences between precipitation categories were not $(\operatorname{Pr}>F=0.4425)$. For the MAEs calculated with detrended yields, the differences between counties were significant $(\operatorname{Pr}>F=$ $0.0053)$ while the differences between precipitation categories were not $(\operatorname{Pr}>F=0.4732)$.

Once again, the significance of the county interaction indicates differences in levels of agreement between different crops and irrigation versus dryland over the precipitation categories. Here, like the temperature categories above, Holt County irrigated maize had the lowest MAE indicating the greatest agreement between simulated and detrended yields. Sorghum had the highest MAE indicating the least agreement except during dry extremes where Franklin is displaced by Butler County irrigated maize (Table 9). Also, the lack of significance of the yield interactions among the precipitation categories suggests that, even though there is variation among crops and irrigation versus dryland, the level of agreement between simulated and both observed and detrended yields does not vary among the normal and extreme precipitation categories. 
Table 9. Mean absolute error (MAE) and mean bias error (MBE) between EPIC yield and observed or detrended yield for precipitation classification and county. Values in $\mathrm{tha}^{-1}$

\begin{tabular}{|lrrrr|}
\hline County & \multicolumn{3}{c}{$\begin{array}{c} \\
\text { Observed yield }\end{array}$} & \multicolumn{2}{c}{ Detrended yield } \\
& MAE & MBE & MAE & MBE \\
\hline Wettest 5 years & & & & \\
Holt & 1.066 & 0.388 & 0.442 & -0.132 \\
Butler & 2.061 & 2.061 & 1.427 & 1.427 \\
Franklin & 1.975 & 1.975 & 1.749 & 1.732 \\
Hall & 1.137 & 0.575 & 1.065 & 0.532 \\
Saunders & 0.860 & -0.860 & 1.191 & -1.191 \\
Jefferson & 1.334 & 1.268 & 0.939 & 0.817 \\
Pawnee & 2.106 & 2.106 & 1.912 & 1.912 \\
& & & & \\
Normal precipitation & $($ middle & 10 years) & & \\
Holt & 0.830 & 0.644 & 0.360 & 0.254 \\
Butler & 1.544 & 1.544 & 1.227 & 1.227 \\
Franklin & 1.932 & 1.932 & 1.740 & 1.732 \\
Hall & 1.584 & 1.584 & 1.102 & 1.086 \\
Saunders & 0.773 & -0.001 & 0.831 & -0.244 \\
Jefferson & 0.801 & -0.158 & 0.753 & -0.357 \\
Pawnee & 1.730 & 1.730 & 1.622 & 1.622 \\
Driest 5 years & & & & \\
Holt & & & & \\
Butler & 0.964 & 0.964 & 0.635 & 0.610 \\
Franklin & 2.643 & 2.643 & 2.061 & 2.061 \\
Hall & 1.258 & 1.232 & 0.874 & 0.874 \\
Saunders & 2.154 & 2.141 & 1.665 & 1.665 \\
Jefferson & 1.098 & -0.673 & 1.429 & -1.401 \\
Pawnee & 0.928 & 0.044 & 0.742 & -0.370 \\
& 1.820 & 1.820 & 1.688 & 1.688 \\
& & & & \\
\hline
\end{tabular}

\section{DISCUSSION AND CONCLUSIONS}

Previously, validations of crop model simulations of yields in response to climate change tended to examine the agreement between simulated and historic observed crop growth over all years combined (inclusive of normal and extreme years). As such, they were little more than affirmation of how well such models represent yields under the contemporary climate, not climate change conditions. We argue that to get a realistic glimpse of how reliable the simulations of such models may be under climate change, the focus should be on how well the models predict observed yields in extreme years which approximate climate change conditions.

Our analyses reaffirm earlier studies which suggest that an important step in validating crop models over historic time series is the removal of the technology bias from the observed yields, which tends to obscure the effect of year-to-year climate variation on yields. We found that a simple linear model of time versus observed yield series produced residuals - we call them detrended yields - that were in better agreement with simulated yields than were the raw observed yields. This last conclusion was supported by the statistically significant difference between MAEs measuring agreement between simulated and observed yields versus MAEs measuring agreement between simulated and detrended yields. Furthermore, the detrended yields were in strong agreement - as indicated by low MBEs and MAEs - with simulated yields of all crops and with dryland and irrigated situations alike.

Our analyses also suggest that the agreement of yields simulated by the EPIC model with detrended (and raw observed) yields were not statistically significantly different among the categories of normal or extreme climate years. Such was true for temperature and precipitation extremes. Though variation in levels of agreement among the 7 counties (differentiated in part by crop species and irrigated versus dryland practices) was statistically significant, no systematic variation among sites with respect to the different climate categories was detectable. Thus, we can accept the null hypothesis stated above. The inescapable conclusion is that EPIC simulates yields as reliably during recent extreme climate years relative to current climate normals as it does during years that are closer to current normals.

The results described above are strongly suggestive that EPIC predictions of detrended yields during extreme warm years, as defined in this study, are as reliable as yield predictions during normal temperature years. This is supported by the low MBE and MAE values and their lack of statistically significant differences among different temperature categories (cold/ hot and normal). EPIC simulated yields do not agree with detrended yields under precipitation extremes in either direction as well as they do under normal precipitation, though simulations of yields in extreme wet years may be more reliable than during extreme dry years based on differences in the MAEs and MBEs. MAEs during dry years are higher than wet years in 4 counties, with the exceptions of Butler, Jefferson and Pawnee. However, we conclude that yield simulations under dry conditions should not be dismissed altogether, since the MAEs over all locations during wet years and dry years are close, 1.25 and $1.30 \mathrm{t} \mathrm{ha}^{-1}$ respectively, and are not significantly different from normal precipitation years, and MBEs are also equal at $0.73 \mathrm{tha}^{-1}$ (Table 7 ).

In conclusion, the EPIC model accurately tracks crop yields under observed departures from current temperature normals that mimic the most certain feature of expected climate change: warming. A common modelgenerated scenario of climate change in midlatitude continental interiors is warming and drying. The reliability of EPIC simulations during extreme dry years is not as high as during warm years, but by no means is it lacking all credibility. Thus, some confidence in EPIC 
simulations of yields under climate warming and drying appears warranted. Of course, higher magnitude extremes under climate change than current observed extremes will challenge this last assertion.

Acknowledgements. We thank Drs A. Weiss, D. Stooksbury and $\mathrm{S}$. Meyer for their reviews of this paper in its various stages and Deanna Batty for her assistance in word processing. This work was partially supported by the Rocky Mountain Research Station of the USDA/Forest Service under Research Agreement 28-C3-731. Twenty percent (\$20000) of this research was funded by the U.S. Department of Energy's (DOE) National Institute for Global Environmental Change (NIGEC) through the NIGEC-Great Plains Regional Center at the University of Nebraska-Lincoln under DOE Cooperative Agreement No. DEFC03-90ER61010. Financial support does not constitute an endorsement by DOE of the views expressed in this article.

\section{LITERATURE CITED}

Curry RB, Peart RM, Jones JW, Boote KJ, Allen LH Jr (1990) Simulation as a tool for analyzing crop response to climate change. Trans Am Soc Agric Eng 33(3):981-990

Easterling WE, Crosson PR, Rosenberg NJ, McKenney MS, Katz LA, Lemon KM (1993) Agricultural impacts of and responses to climate change in the Missouri-IowaNebraska-Kansas (MINK) region. Clim Change 24:23-62

Easterling WE, Rosenberg NJ, McKenney MS, Jones CA, Dyke PT, Williams JR (1992) Preparing the erosion productivity impact calculator (EPIC) model to simulate crop response to climate change and the direct effects of $\mathrm{CO}_{2}$. Agric For Meteorol 59:17-34

Jones JW, Jagtap SS, Hoogenboom G, Tsuji GY (1989) The structure and function of DSSAT In: International Benchmark Sites Network for Agrotechnology Transfer (IBSNAT) (ed) Decision Support System for Agrotechnology Transfer, IBSNAT Symposium, Part I: Symposium Proceedings

Kiniry JR, Spanel DA, Williams JR, Jones CA (1990) Demonstration and validation of crop grain yield simulation by EPIC EPIC-Erosion Productivity Impact Calculator. 1 Model Documentation. US Dep Agric, Agric Res Serv Tech Bull 1768:220-234

McKenney MS, Easterling WE, Rosenberg NJ (1992) Simulation of crop productivity and responses to climate change in the year 2030; the role of future technologies, adjustments and adaptations. Agric For Meteorol 59:103-137

McQuigg JD, Thompson L, Duc SLe, Lockard M, McKay G (1973) the influence of weather and climate on United States grain yields: bumper crops or drought. Rep to the Associate Administrator for Environmental Monitoring and Prediction, NOAA, US Dep Commerce

Mearns LO (1993) Implication of global warming for climate variability and the occurrence of extreme climate events In: Wilhite DA (ed) Drought assessment, management, and planning: theory and cases studies, Chap 7. Kluwer Academic Publishers, Boston, p 109-132

Editor: V. Meentemeyer, Athens, Georgia, USA
Meyer SJ, Ameri SA, Hubbard KG (1996) ClimProb: software for assisting climate-related decision making. J Prod Agric (in press)

Nicks AD (1974) Stochastic generation of the occurrence, pattern, and location of maximum amount of daily rainfall. In: US Dept of Agriculture (ed) Proc Symp Statistical Hydrology, Aug-Sept 1971, Tucson, AZ. US Dep Agric, Misc Publ 1275:154-171

Parry ML, Carter TR (1988) The assessment of effects of climatic variations on agriculture: a summary of results from studies in semi-arid regions. In: Parry ML, Carter TR, Konjin NT (eds) The impact of climatic variations on agriculture. Vol 2. Assessments in semi-arid regions. Kluwer, Dordrecht

Protopapas AL, Bras RL (1993) Effects of weather variability and soil parameter uncertainty on the soil-crop-climate system. J Climate 6(4):645-660

Richardson CW (1981) Stochastic simulation of daily precipitation, temperature, and solar radiation. Water Resour Res 17(1):182-190

Richardson CW, Wright DA (1984) WGEN: a model for generating daily weather variables. US Dep Agric, Agric Res Ser, ARS-8

Ritchie JT (1991) Specifications of the ideal model for predicting crop yields. In: Muchow RC, Bellamy JA (eds) Climate risk in crop production: models and management for the semiarid tropics and subtropics. CAB International, Wallingford, p 97-122

Rosenberg VJ, McKenney MS, Easterling WE, Lemon KM (1992) Validation of EPIC model simulations of crop responses to current climate and $\mathrm{CO}_{2}$ conditions: comparisons with census, expert judgement and experimental plot data. Agric For Meteorol 59:35-51

Rosenzweig C, Parry M (1994) Potential impact of climate change on world food supply. Nature 367:133-138

Sakamoto CM (1978) The Z-index as a variable for crop yield estimation. Agric Meteorol 19:305-314

Smith JB, Tirpak D (1990) The potential effects of global climate change on the United States. Hemisphere Pub Corp, New York

Spitters CJT (1990) Crop growth models: their usefulness and limitations. Acta Hort 267:349-368

Tegart W, Sheldon G, Griffiths D (eds) (1990) Climate change: The Intergovernmental Panel on Climate Change (IPCC) impacts assessments. Australian Government Publishing Service, Canberra

Thornton PK, Bent JB, Bacsi Z (1991) A framework for crop growth simulation model applications. Agric Syst 37 : $1-330$

USDA (1990) The second RCA appraisal: soil, water and related resources on nonfederal land in the United States. US Dep Agric, Misc Publ 1482

USDA (1971-1990) County level estimates. National Agricultural Statistics Services, US Dep Agric, Washington, DC

Williams JR, Jones CA, Dyke PT (1984) A modeling approach to determining the relationship between erosion and soil productivity. Trans Am Soc Agric Eng 27:129-144

Williams JR, Jones CA, Dyke PT (1990) The EPIC model. EPIC-Erosion/Productivity Impact Calculator. 1. Model Documentation. US Dep Agric, Agric Res Serv Tech Bull $1768: 3-92$

Manuscript first received: January 6, 1995

Revised version accepted: October 20, 1995 